\title{
Spatiotemporal behavior of a large-scale landslide at Mt. Onnebetsu-dake, Japan, detected by three L-band SAR satellites
}

\author{
Youichiro Takada ${ }^{*}$ (ID and George Motono ${ }^{2}$
}

\begin{abstract}
We applied differential InSAR analysis to the Shiretoko Peninsula, northeastern Hokkaido, Japan. All the interferograms of long temporal baseline ( 3 years) processed from SAR data of three L-band satellites (JERS-1, ALOS, ALOS2) commonly indicate remarkable phase changes due to the landslide movement at the southeastern flank of Mt. Onnebetsu-dake, a Quaternary stratovolcano. The area of interferometric phase change matches to known landslide morphologies. Judging from the timing of the SAR image acquisitions, this landslide has been moving at least from 1993 to the present. Successive interferograms of 1-year temporal baseline indicate the temporal fluctuation of the landslide velocity. Especially for the descending interferograms, the positive line-of-sight (LOS) length change, which indicates large subsidence relative to the horizontal movement, is observed in the upslope section of the landslide during 1993-1998, while the negative LOS change is observed in the middle and the downslope section after 2007 indicating less subsidence. The landslide activity culminates from 2014 to 2017: the eastward and the vertical displacement rates reach $\sim 6$ and $\sim 2 \mathrm{~cm} / \mathrm{yr}$, respectively. Utilizing high spatial resolution of ALOS and ALOS-2 data, we investigated velocity distribution inside the landslide. During 2007-2010, the eastward component of surface displacement increases toward the east, implying that the landslide extends toward the east. During 2014-2017, the vertical displacement profile exhibits spatially periodic uplift and subsidence consistent with surface gradient, which indicates the ongoing deformation driven by gravitational force. Heavy rainfall associated with three typhoons in August 2016 might have brought about an increase in the landslide velocity, possibly due to elevated pore-fluid pressure within and/or at the base of the landslide material. Also, annual rainfall would be an important factor that prescribes the landslide velocity averaged over 3 years.
\end{abstract}

Keywords: Slow-moving landslide, L-band, InSAR, JERS-1, ALOS, ALOS-2, Hokkaido

\section{Introduction}

In monsoonal Asia, landslides due to heavy rainfall frequently caused severe damages. To mitigate landslide damages, it is essentially important to map the landslide-prone areas in advance. The Japan Seismic Hazard Information Station (J-SHIS) provided by the National Research Institute for Earthquake Science and Disaster Resilience (NIED) extensively integrated such potential

\footnotetext{
*Correspondence: takaday@sci.hokudai.ac.jp

1 Department of Earth and Planetary Sciences, Hokkaido University,

N10W8, Kita-ku, Sapporo 060-0810, Japan

Full list of author information is available at the end of the article
}

landslide information in Japan (National Research Institute for Earth Science and Disaster Prevention 2020). To step forward, two pieces of additional information are required: (1) current velocity of the landslide movement and its temporal change; (2) internal deformation of the landslide mass. Space-borne Synthetic Aperture Radar (SAR) is an ideal tool to investigate the above-mentioned points. By taking phase difference between temporally separated two SAR images, called interferometric SAR (InSAR), we can obtain surface velocity maps with a very high spatial resolution (e.g., Massonnet et al. 1993). More specifically, what we can measure with InSAR is called as line-of-sight (LOS) displacements: the inner product of 
surface displacement vectors and unit vectors of radar incidence direction. So far, many previous studies have applied the InSAR technique to landslide movements using C-band satellites (e.g., Hilley et al. 2004; Colesanti and Wasowski, 2006). The landslide in densely vegetated areas have also been detected by InSAR analysis of L-band SAR data acquired by ALOS (e.g., Zhao et al. 2012; Handwerger et al. 2013). Recently, the high spatial resolution of ALOS-2, the latest L-band SAR satellite, has been utilized to detect landslide movements (e.g., Sato and Une, 2016; Nishiguchi et al. 2017; Fujiwara et al. 2017). Furthermore, Hu et al. (2019) applied the InSAR technique using both ALOS and ALOS-2 data to a slowmoving landslide in California, USA. In this study, we applied InSAR analysis using three L-band satellites to investigate a large-scale slow-moving landslide in the Shiretoko Peninsula, Japan.

The Shiretoko Peninsula, one of the UNESCO world heritages, locates at the northeastern part of Hokkaido (Fig. 1), where many landslide geomorphologies have been identified by aerial photographs (Ito, 1994, 1996). One of the largest landslide morphologies in this region has been found at the southeastern flank of the Mt.

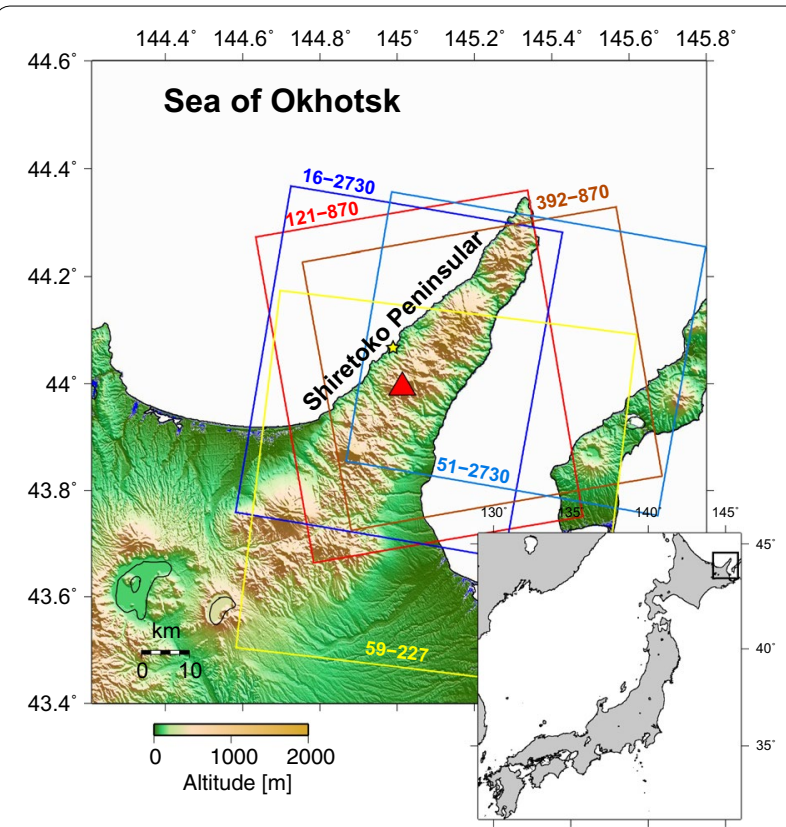

Fig. 1 Location map of study area. Red triangle indicates Mt. Onnebetsu-dake. Star indicates the Utoro town. Surface elevation is from the hole-filled Shuttle Radar Topography Mission (SRTM) V4.1 (Jarvis et al. 2008). Colored frames indicate SAR data coverages. Red: ALOS-2 ascending (Path 121, Frame 870), blue: ALOS-2 descending (Path 16, Frame 2730), brown: ALOS ascending (Path 392, Frame 870), light blue: ALOS descending (Path 51, Frame 2730), yellow: JERS-1 descending (Path 59, Row 227). Inset shows the Japan arc. Thick rectangle indicates the study area
Onnebetsu-dake, a Quaternary stratovolcano (height above sea level: $1330 \mathrm{~m}$ ). The current volcanic activity of Mt. Onnebestu-dake is very low, and its edifice is highly dissected. Figure 2 shows the topographic map of the proximity of Mt. Onnebetsu-dake, in which a gentle slope extending to the southeast is the landslide morphology studied in this paper. This landslide area is bounded by two tributaries of the Shunkarikotan River as shown in Fig. 2. The length and width of this landslide are 4.5 and $1.6 \mathrm{~km}$, respectively, which associates the main scarp with a relative height of $250 \mathrm{~m}$ and several lateral scarps especially along its southwest margin (Ito, 1994). Within the landslide mass, we can observe minor scarps, pressure ridges, and depressions (small lakes) formed by the landslide activities (Ito, 1994). The current morphology was formed by large-scale rock-slump-type movements and subsequent rock-slides and debris flows (Ito, 1994). The current velocity of this landslide is poorly known, mainly due to many obstacles to the field observations. The Shiretoko Peninsula is covered by primeval forest (no trail in the Mt. Onnebetsu-dake) and well known as a dense population of brown bears. Also, the Shiretoko Peninsula is characterized by heavy snow-fall in winter and spring, which makes it difficult to conduct

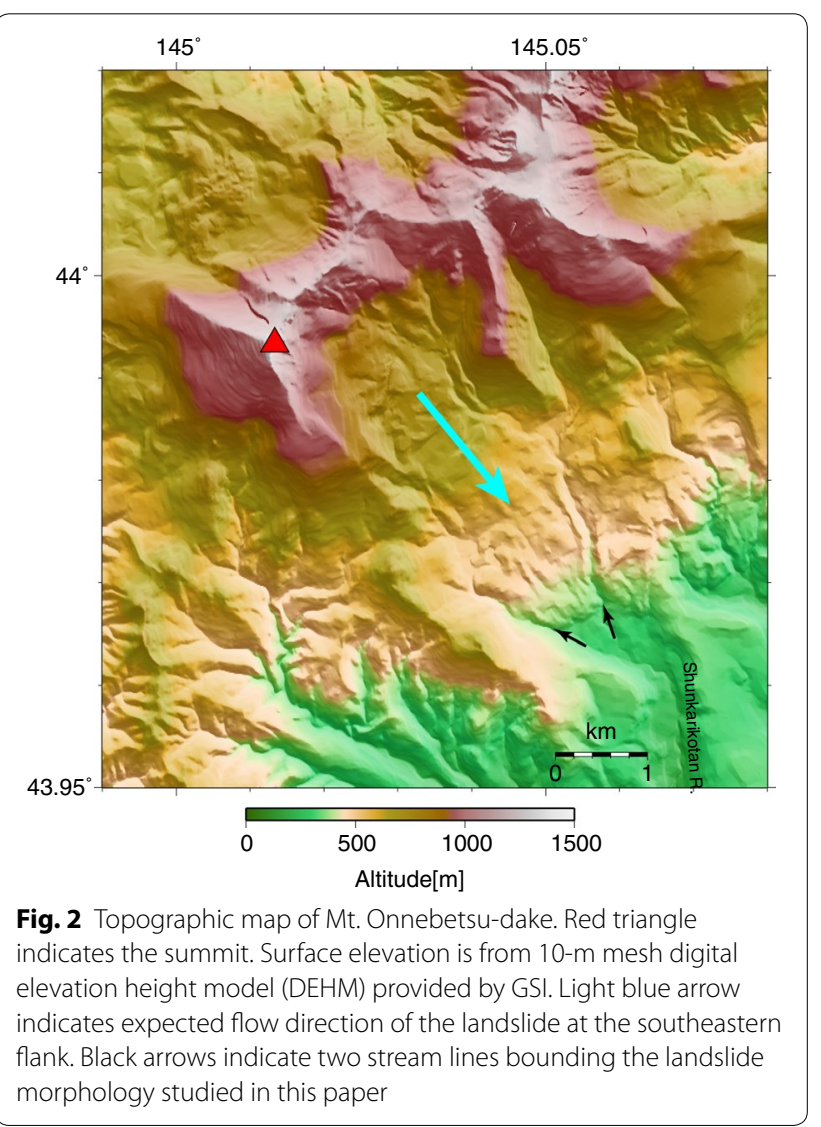


ground-based geodetic observations. To overcome such difficulties, in this study, we use a series of InSAR images acquired by L-band SAR satellites taking advantage of high interferometric coherence. We use three successive L-band satellites, JERS-1 (1992-1998), ALOS (2006-2011), and ALOS-2 (2014 to present) to investigate the spatiotemporal behavior of the landslide at the southeastern flank of Mt. Onnebetsu-dake. We further investigate its internal velocity field by making the most of ALOS and ALOS-2 high spatial resolution. Finally, we discuss the relationship between landslide activity and the amount of precipitation, especially under abnormal weather conditions.

\section{Method}

We processed interferograms of SAR data acquired by JERS-1, ALOS, and ALOS-2 with the GAMMA software suite (Wegmüller and Werner, 1997). To remove topographic fringes, we used a 10-m mesh digital elevation height model (DEHM) released from the Geospatial Information Authority of Japan (GSI). The original data in this area have been acquired on 1976, and improved on 1995 and 2017, which is digitized and provided by
GSI. We adopted the minimum cost flow method (Costantini, 1998) for phase unwrapping. The interferometric pairs are listed in Table 1 . The SAR data coverages are illustrated in Fig. 1, where the paths and frames ('lows' for JERS-1) of each satellite acquisition are indicated as well. All the ALOS-2 data used in this study were acquired in right-looking mode.

It should be noted that the SAR images acquired in winter and spring cannot be used for interferometry because the snow cover causes coherence loss. Considering such limitation of useful InSAR images, we decided not to apply any advanced time-series analysis at this stage (e.g., Feretti et al. 2001; Berardino et al. 2002). Also, if the landslide movement changes with time drastically, the minimum norm solutions may smooth out the temporal change in velocities. Thus, in this study, we opt to compare a series of interferograms with each other to extract the temporal behavior of the landslide.

We aim at flattening the systematic noise in the proximity of the landslide. For this purpose, each interferogram was corrected by a two-step approach. First, we modeled the long-wavelength phase trend by a quadratic function, and removed it. The removed components are

Table 1 Interferometric pairs used in this study

\begin{tabular}{|c|c|c|c|c|c|c|c|}
\hline Satellite & $\begin{array}{l}\text { Direction (Asc/ } \\
\text { Dsc) }\end{array}$ & Master & Slave & $\mathrm{Bp}(\mathrm{m})$ & Inc (deg.) & Mode & Interval (days) \\
\hline JERS-1 & Dsc & 1993/08/12 & 1995/07/17 & 363 & 38.8 & - & 704 \\
\hline JERS-1 & Dsc & 1995/07/17 & 1998/06/07 & 835 & 38.8 & - & 1056 \\
\hline ALOS & Asc & 2007/07/05 & 2010/07/13 & 1041 & 38.7 & DD & 1105 \\
\hline ALOS & Asc & 2007/07/05 & 2008/07/07 & -1174 & 38.7 & DD & 369 \\
\hline ALOS & Asc & 2008/07/07 & $2009 / 08 / 25$ & 409 & 38.7 & DD & 415 \\
\hline ALOS & Asc & $2009 / 08 / 25$ & 2010/07/13 & 1807 & 38.7 & DD & 323 \\
\hline ALOS & Dsc & 2007/08/19 & 2010/07/12 & 1220 & 38.8 & SS & 1059 \\
\hline ALOS & Dsc & 2007/08/19 & 2008/07/06 & -1065 & 38.8 & SD & 323 \\
\hline ALOS & Dsc & 2008/07/06 & 2009/08/24 & -206 & 38.8 & SD & 415 \\
\hline ALOS & Dsc & $2009 / 08 / 24$ & 2010/07/12 & 2495 & 38.8 & SS & 323 \\
\hline ALOS-2 & Asc & $2014 / 09 / 22$ & $2017 / 06 / 12$ & -176 & 39.7 & U & 995 \\
\hline ALOS-2 & Asc & $2014 / 09 / 22$ & 2015/06/29 & -224 & 39.7 & U & 281 \\
\hline ALOS-2 & Asc & $2015 / 06 / 29$ & $2016 / 06 / 27$ & 171 & 39.7 & U & 365 \\
\hline ALOS-2 & Asc & $2016 / 06 / 27$ & 2017/06/12 & -123 & 39.7 & U & 349 \\
\hline ALOS-2 & Asc & 2017/06/12 & 2019/06/10 & 155 & 39.7 & U & 728 \\
\hline ALOS-2 & Dsc & 2014/09/15 & $2017 / 08 / 28$ & -134 & 39.7 & U & 1079 \\
\hline ALOS-2 & Dsc & 2014/09/15 & $2015 / 09 / 28$ & -85 & 39.7 & U & 379 \\
\hline ALOS-2 & Dsc & $2015 / 09 / 28$ & $2016 / 08 / 29$ & 98 & 39.7 & U & 337 \\
\hline ALOS-2 & Dsc & $2016 / 08 / 29$ & $2017 / 08 / 28$ & -147 & 39.7 & U & 365 \\
\hline ALOS-2 & Dsc & $2017 / 08 / 28$ & 2019/11/18 & -8 & 39.7 & U & 812 \\
\hline ALOS-2 & Dsc & $2017 / 08 / 28$ & 2018/11/19 & -17 & 39.7 & U & 448 \\
\hline ALOS-2 & Dsc & $2018 / 11 / 19$ & 2019/11/18 & 9 & 39.7 & U & 364 \\
\hline
\end{tabular}

Asc and Dsc are the abbreviations of ascending and descending orbit, respectively, $B p$ means perpendicular baseline, Inc means incidence angle at scene center, $S S$ beam mode of master and slave data are FBS (fine beam single polarization), DD beam mode of master and slave is FBD (fine bean dual polarization), SD combination between FBS and FBD, $U$ beam mode of master and slave is ultra-fine. Beam mode of JERS-1 SAR is unique 
typically due to orbit estimation error, ionospheric and/ or tropospheric disturbances with length-scale much larger than that of landslides. Second, we cropped out the proximal area of Mt. Onnebestu-dake. In the cropped area, we still find a remnant of the long wave-length noise as well as a height dependence of the interferometric phase due to an elevation-correlated tropospheric noise. For all the interferograms, we modeled such systematic noise in the cropped area by a linear function of height along with linear function in space (ramp), and removed it. In the following part of this paper, the cropped areas are shown as blow-up figures.

\section{Overall activities}

First, to grasp overall landslide activities, we focus on the long temporal baseline pairs by which the signal-tonoise ratio can be enhanced. Figure 3 indicates the interferograms taken from descending orbit, spanning about 3 years ( 2 years for Fig. $3 g$ and $h$ ). At the southeast flank of the Mt. Onnebestsu-dake, we see a remarkable line-ofsight (LOS) length change in an area elongated toward the southeast in the interferograms of JERS-1 (Fig. 3a), ALOS (Fig. 3c) and ALOS-2 (Fig.3e and g). In this paper, we define positive LOS length changes as surface movements away from the satellite. We set the reference point (black dot in Fig. 3) within $1 \mathrm{~km}$ distance from the landslide. The blow-up figures of the landslide area (Fig. 3b, $\mathrm{d}, \mathrm{f}, \mathrm{h}$ ) indicate that the LOS displacement inside the landslide is not uniform, which will be discussed later in detail. Using ALOS and ALOS-2 images, we also processed ascending interferograms spanning about 3 years (Fig. 4, 2 years for Fig.4e and f). All the ascending interferograms clearly display the positive LOS displacement due to the landslide movement at the southeastern flank of the Mt. Onnebetsu-dake. Thus, averaging over a long (2-3 year) time-scale, it is highly likely that the landslide has been moving persistently from 1995 (actually 1993 as shown in the next section) to the present at a rate slower than $7.3 \mathrm{~cm} / \mathrm{yr}$ (Fig. 5). Such temporal behavior is called as "slow-moving landslide" (e.g., Hilley et al. 2004; Handwerger et al. 2013; $\mathrm{Hu}$ et al. 2019). Incidentally, if the direction of surface movement coincides to that of steepest gradient (roughly 9 degrees down to N147E in the middle stream area), the LOS velocity of $7.3 \mathrm{~cm} / \mathrm{yr}$ corresponds to the surface velocity of $20.0 \mathrm{~cm} / \mathrm{yr}$.

Figure 6 indicates the landslide morphologies provided by J-SHIS (https://www.j-shis.bosai.go.jp/en/) draped over the ALOS-2 interferogram indicated in Fig. 3f (2014/09/15-2017/08/28). It should be noted that the reference point does not locate within any landslide morphology. From Fig. 6, we understand that (1) the area of LOS length-change coincides with mapped landslide morphologies (Fig. 6b), and (2) many other landslide morphologies in and around Mt. Onnebetsu-dake remain stable (Fig. 6a). The mapped landslide morphologies indicate that the landslide area is expected to flow down in the southeast direction as a whole (Fig. 2), which is consistent with the overall trend of Figs. 3 and 4: negative and positive LOS changes from descending and ascending orbits, respectively.

\section{Internal velocity structure}

In this section, we focus on the internal deformation pattern of the landslide by decomposing the surface displacement vectors into the quasi-east and the quasivertical components lying in the plane including 2 LOS vectors for ascending and descending interferograms (Fujiwara et al. 2000). Hereafter, we call the quasi-east and the quasi-vertical simply as east (or eastward) and vertical, because the former is almost the same as the east and the latter deviates less than 8 degrees from vertical. We selected ALOS and ALOS-2 interferograms with more than 2-year temporal baseline to enhance the signal-to-noise ratio. Figure 7 indicates the eastward and the vertical components of the surface velocities for 20072010, 2014-2017, and 2017-2019. Overall, the eastward component is much larger than vertical component; for 2014-2017, the former reaches $6 \mathrm{~cm} / \mathrm{yr}$ while the latter is about $-2 \mathrm{~cm} / \mathrm{yr}$ at most. The vertical velocities in Fig. 7 display remarkable temporal change in the spatial patterns as described below.

During 2007-2010 (Fig. 7b), the uplift rate increases from west to east, and culminates along the eastern edge bounded by a stream flowing down to the southeast. Combined with the eastward increase in the eastward component (Fig. 7a), the landslide mass is expanding toward the east and would be burying the stream.

During 2014-2017, the spatially periodic movement can be identified in the vertical component (Fig. 7d). Figure 8 indicates the profile of the surface velocities as well as a surface gradient along the section line AA' in $^{\prime}$ Fig. $7 \mathrm{~d}$. Along the section AA', the vertical velocity and the surface gradient changes in harmony (Fig. 8a): rapid subsidence where relatively steep surface slope, slow subsidence or slow uplift where very shallow to upslope, which implies that the internal deformation of the landslide is essentially driven by gravitational force. In Fig. 7d, each area of relative subsidence trends in the transverse direction (i.e., NE-SW to ENE-WSW), that is, perpendicular to the entire landslide morphology, which implies the southeast movements of landslide mass as a whole. Figure $8 \mathrm{~b}$ indicates the eastward components of surface velocities along the section $\mathrm{AA}$, which dominantly shows eastward movement with a long wave-length undulation ranging $\sim 2$ to $\sim 4.5 \mathrm{~cm} / \mathrm{yr}$. The slow eastward movements around 145.03 E and 145.046 E (Fig. 8b) are in 
good accordance with the fast uplifts there (Fig. 8a). For the latter (145.046 E), the surface gradient is the largest (slightly upslope) implying that the downslope mass transportation was obstructed by the upslope morphology, and the transported material was clogged up to go upward.

From 2017 to 2019, Fig. 7f does not display distinct vertical motion in comparison to the background noise level over the entire region. The eastward component of surface velocity indicates a gradual increase toward the internal part, but internal deformation is very slow during this period.

\section{Temporal change of landslide activities}

In this section, we focus on the temporal change of the landslide activities. Considering no ascending data acquisition by JERS-1, we begin with comparing descending interferograms that cover a longer period than ascending ones. Although the landslide movements are commonly detected by three satellites (Fig. 3), the LOS velocities are not constant in time. The maximum LOS velocities in the processed interferograms are compiled in Fig. 5. The JERS- 1 interferograms indicate length increase in the LOS direction at rates from 3.1 to $4.1 \mathrm{~cm} / \mathrm{yr}$ (Figs. 3b, 5, 9a), while ALOS and ALOS-2 descending interferograms show clear length shortening (Fig. 3d, f, h). The interpretation of this flip in LOS sign will be described in a later section. Figure 5 indicates that the landslide velocity is relatively low $(-3.0 \mathrm{~cm} / \mathrm{yr})$ from 2007 to 2010 , then is raised to $-4.7 \mathrm{~cm} / \mathrm{yr}$ from 2014 to 2017 , and declines to $-0.7 \mathrm{~cm} / \mathrm{yr}$ from 2017 to 2019 . The same trend is found in the ascending interferograms (Figs. 4 and 5); the velocity is low $(1.6 \mathrm{~cm} / \mathrm{yr})$ during $2007-2010$, then is increased to $7.3 \mathrm{~cm} / \mathrm{yr}$ during 2014-2017, and declines to $1.8 \mathrm{~cm} / \mathrm{yr}$ from 2017 to 2019.

To investigate the temporal change much in detail, for both of the ascending and descending orbits, we split the ALOS and ALOS-2 interferograms spanning 3 years (2 years after 2017) into successive interferograms over 1 year, respectively (Figs. 9 and 10). We included a JERS-1 interferogram spanning 1993-1995 in Fig. 9, for reference. The maximum LOS velocities are compiled in Fig. 5 as well, where it should be noted that the maximum velocity of each 3 -year interferogram does not agree with an average of maximum velocities over 3 interferograms of 1-year temporal baseline because the fastest moving point is changing with time. The fastest moving point strongly reflects the local deformation especially at the toe and along the stream running northeast of the landslide area (Figs. 3, 4, 9, 10). To grasp the entire activities, we calculated the LOS velocities averaged over the landslide area as defined in Fig. 3b, by which the difference between the long-term and the short-term maximum (minimum) velocities are mitigated (Fig. 5). For ascending orbit, we could not make 1-year interferograms during 2017-2018 and 2018-2019 because SAR image was acquired only in the snow season in 2018. From 2007 to 2010, the LOS velocities over entire landslide mass are quite small (Figs. 9 and 10), and often difficult to distinguish from the surrounding areas. During 2009-2010, the fastest LOS velocity in descending image reaches $-6.1 \mathrm{~cm} / \mathrm{yr}$ (marked by a white dot in Fig. 9d), which, however, does not indicate remarkable reactivation of whole landslide area as represented by the averaged rates of $-1.3 \mathrm{~cm} / \mathrm{yr}$ (Fig. 5). From 2014 to 2017, the overall velocities get higher than 2007-2010 for both ascending and descending orbit that reach $15.9 \mathrm{~cm} /$ $\mathrm{yr}$ and $-14.9 \mathrm{~cm} / \mathrm{yr}$, respectively (Figs. 5,9,10). During this period, the LOS velocity seems to fluctuate. In concrete, the descending image exhibits sudden speed-up during 2015/09/28-2016/08/29 (Fig. 9f). On the other hand, the ascending image displays relatively low velocity in 2015/06/29-2016/06/27 (Fig. 10e, but higher than 2007-2010). Such differences between the ascending and the descending images may be explained by (1) temporal change in relative amount of horizontal and vertical component (i.e., direction of surface motion), or by (2) an abnormal increase in precipitation in July and/or August of 2016 which is reflected only on the descending image.

\section{Discussion}

In this section, first, we focus on the cause of positive LOS displacement in the descending interferograms taken by JERS-1 during 1993-1998 (Figs. 3b and 9a). In principle, LOS displacements are strongly dependent on radar incidence angles. For example, smaller incidence angles make interferometric phase changes more sensitive to vertical components of surface displacements. However, the incidence angle of JERS-1 SAR data is almost the same as that of ALOS and ALOS-2 (Table 1),

(See figure on next page.)

Fig. 3 Descending interferograms of long ( 3 year) temporal baseline draped over shaded relief. All the interferograms have been unwrapped. a 1995/07/17-1998/06/07. c 2007/08/19-2010/07/12. e 2014/09/15-2017/08/28. g 2017/08/28-2019/11/18. b, d, f, h Are blow-up figures of the landslide area indicated by white frame in $\mathbf{a}, \mathbf{c}, \mathbf{e}, \mathbf{g}$, respectively. Black dot in $\mathbf{b}, \mathbf{d}, \mathbf{f}, \mathbf{h}$ indicates the reference point. Black line in $\mathbf{b}$ indicates the landslide area used for calculation of averaged displacement rates. White dot indicates the fastest moving point within the landslide area. The orbit and LOS directions are indicated by black and red arrows, respectively. Red triangle indicates the summit of Mt. Onnebetsu-dake 

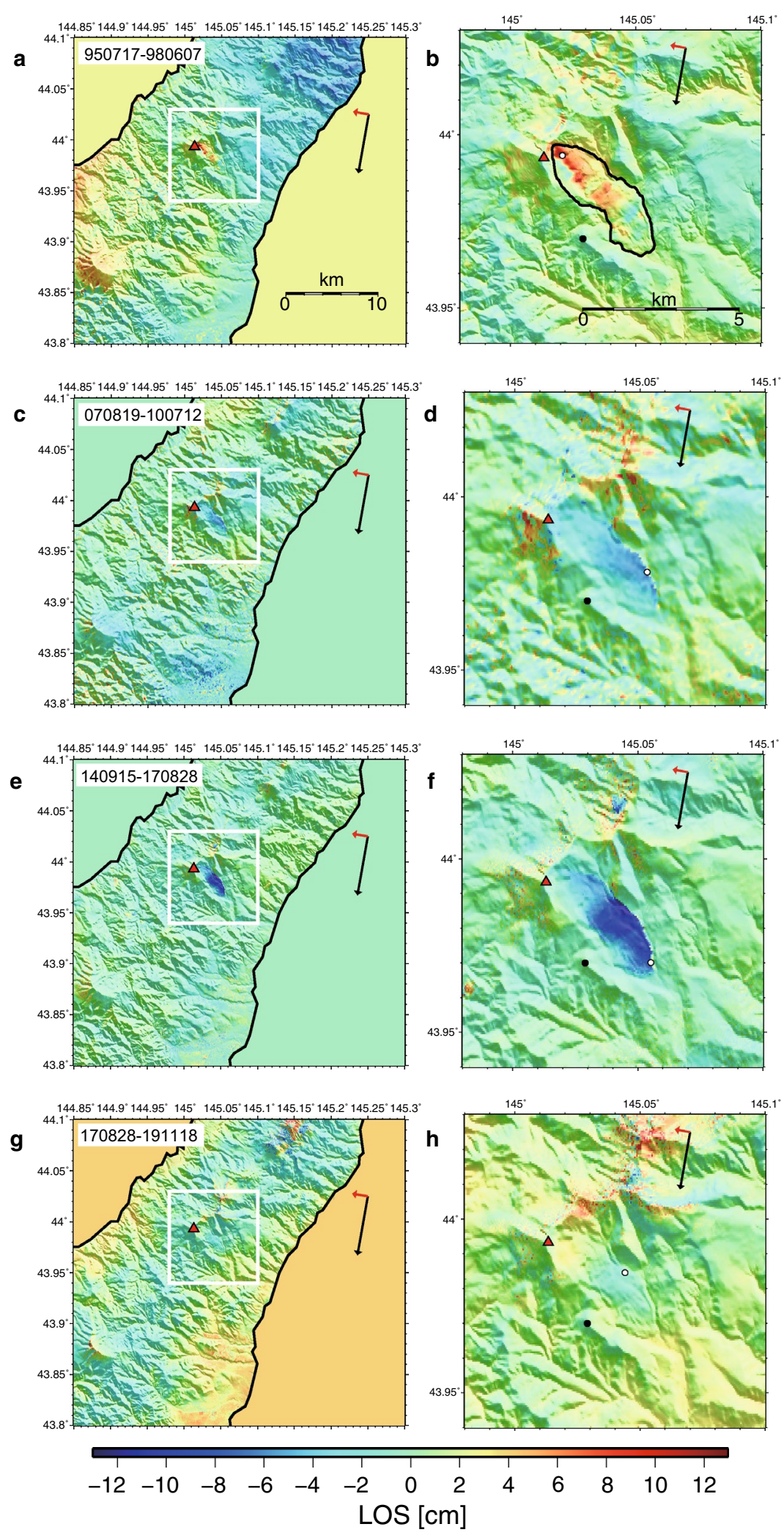
a

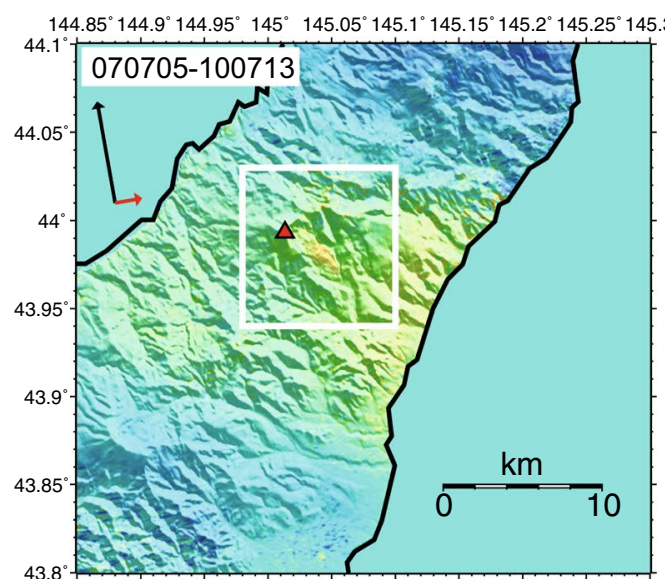

$44^{\circ}$

$145^{\circ} \quad 145.05^{\circ}$

$45.1^{\circ}$

$43.95^{\circ}$
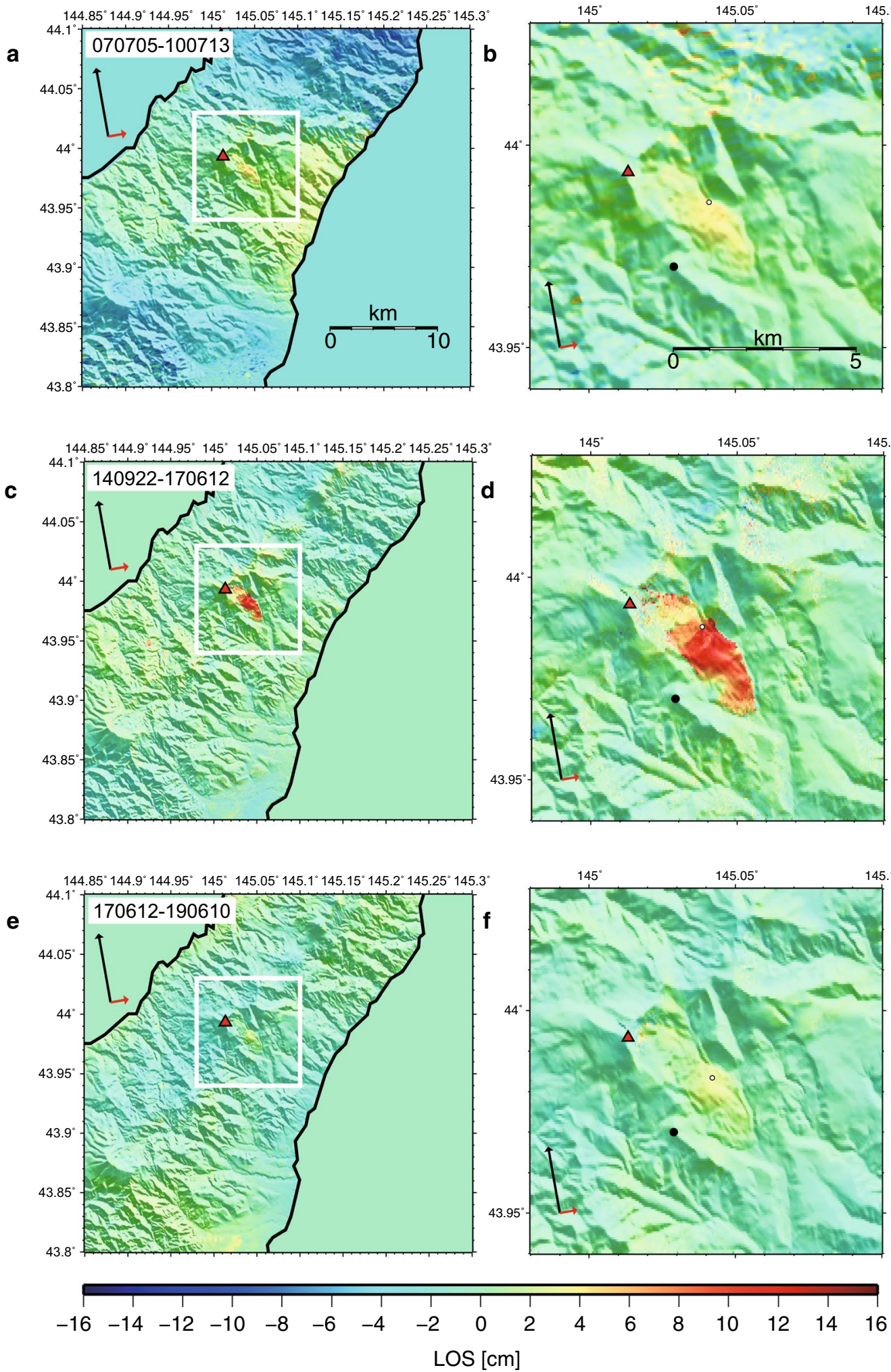

Fig. 4 Ascending interferograms of long ( 3 year) temporal baseline. All the interferograms have been unwrapped. a 2007/07/05-2010/07/13. c 2014/09/22-2017/06/12. e 2017/06/12-2019/06/10. b, d, f Are blow-up figures of the landslide area indicated by white frame in a, c, e, respectively. Black dot in $\mathbf{b}, \mathbf{d}$, $\mathbf{f}$ indicates the reference point. White dot indicates the fastest moving point within the landslide area. The orbit and LOS directions are indicated by black and red arrows, respectively. Red triangle indicates the summit of Mt. Onnebetsu-dake 
a

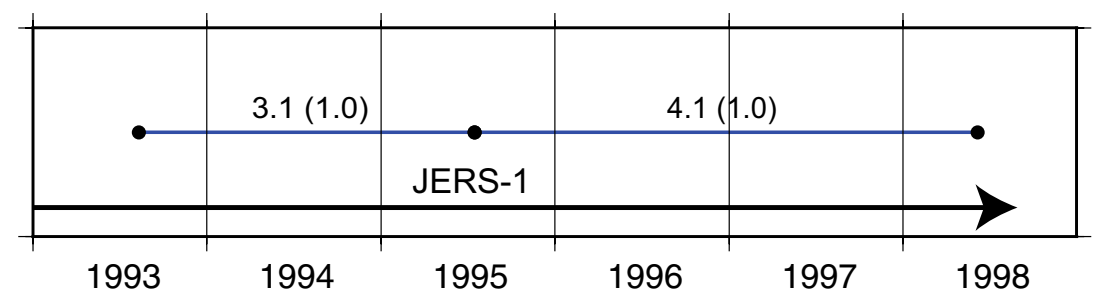

b

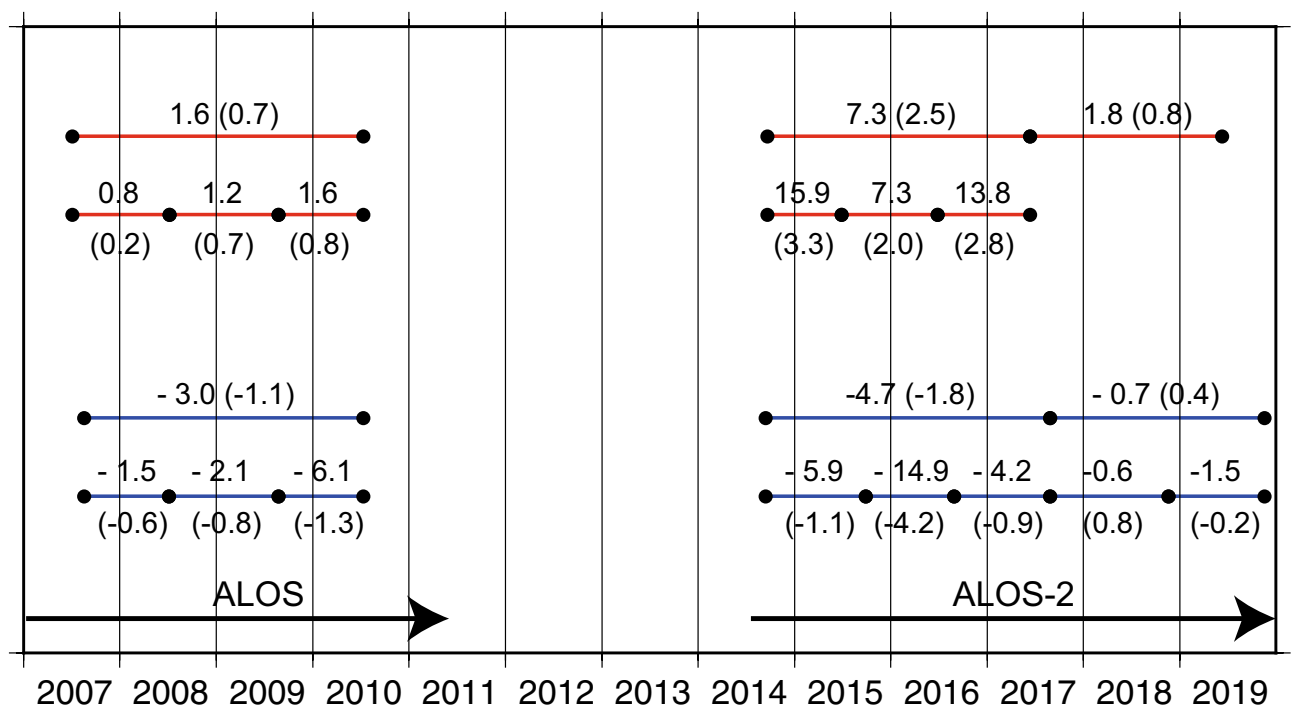

Fig. 5 Temporal baselines of processed interferograms for $\mathbf{a}$ JERS-1 and for $\mathbf{b}$ ALOS and ALOS-2. Red and blue lines indicate ascending and descending orbit, respectively. Black dot represents date of acquisition. Number stands for the maximum LOS velocity (cm/yr) of the corresponding interferogram. Number in parenthesis stands for the LOS velocity averaged over the landslide area defined in Fig. 3 b. Positive value means surface movement away from satellite

which, therefore, does not account for the change in LOS displacement from positive (1993-1998) to negative (2007-2010 and 2014-2019). The positive LOS displacements in the JERS-1 interferograms are observed in the upslope section of the landslide (Figs. 3b and 9a), while the negative LOS displacements in ALOS and ALOS-2 are mainly observed in the middle to the downslope section of the landslide (e.g., Fig. $3 \mathrm{~d}$ and $\mathrm{f}$ ). Following the mass conservation law, it is widely observed that the upstream area of active landslides subsides due to material depletion, and that the provided material flows down along gentle slope of the downstream area (e.g., Varnes, 1978; Hu et al. 2018). Let us consider the geometric relationship between the LOS direction and topographic features under such situation (Fig. 11). The upslope section is characterized by steep scarps that enhance the surface subsidence rather than horizontal motion. The downslope section, on the other hand, is characterized by shallow deposit and gentle slopes that prompt the horizontal motion rather than surface subsidence. Thus, the positive and negative LOS displacements would be preferable at the upslope and the downslope sections, respectively, as illustrated in Fig. 11. Not to mention, however, the spatiotemporal change of the LOS displacement that we observed cannot be explained solely by above-mentioned geometrical relationship. We should keep in mind that complex hydraulic systems can cause such enigmatic behavior of slow-moving landslides (e.g., Handwerger et al. 2013; Hu et al. 2019). For example, heterogeneously high pore-fluid pressure at a limited area may reduce the local surface slope angle supported by internal and basal friction (e.g., Davis et al. 1983). Furthermore, an abnormal increase in pore-fluid pressure may reduce the frictional strength (e.g., Terzaghi 1950), which may account for such remarkable temporal change. Thus, to better understand such spatiotemporal behavior, we have to constrain the hydraulic properties by field observations as well as geodetic surveys.

Next, we discuss the effect of height error of the DEHM on the periodic uplift shown in Figs. $7 \mathrm{~d}$ and $8 \mathrm{a}$. The apparent LOS displacement $\Delta u$ caused by the DEHM error $\Delta h$ is written as: 
a

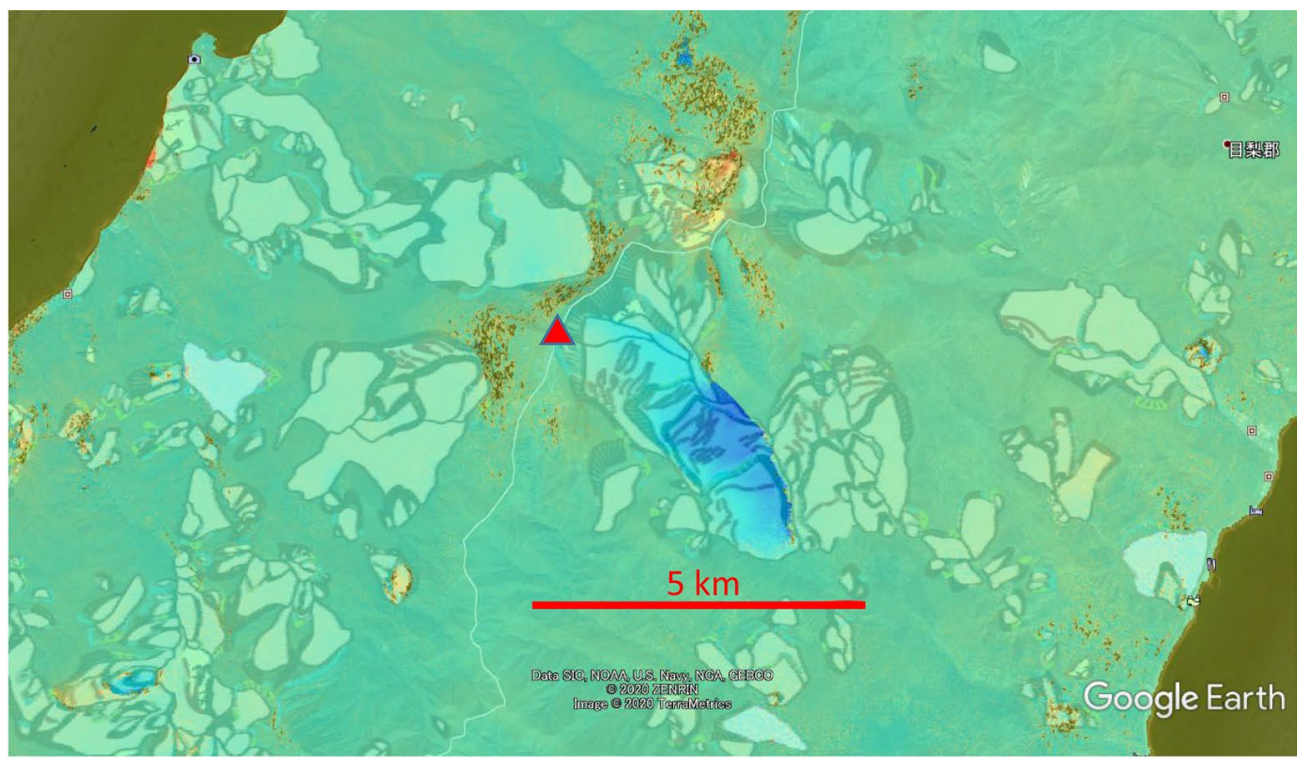

b


Lunar or crown cracks, multiple scarps and ridges.



Definite margin of the moving mass

Fig. 6 Landslide morphologies drawn over ALOS-2 descending interferogram (2014/09/15-2017/08/28). a Regional map. b Zoom-up figure of the study area. The landslide morphologies are provided by J-SHIS. Red triangle indicates the summit of Mt. Onnebetsu-dake. We used Google Earth to prepare this figure 


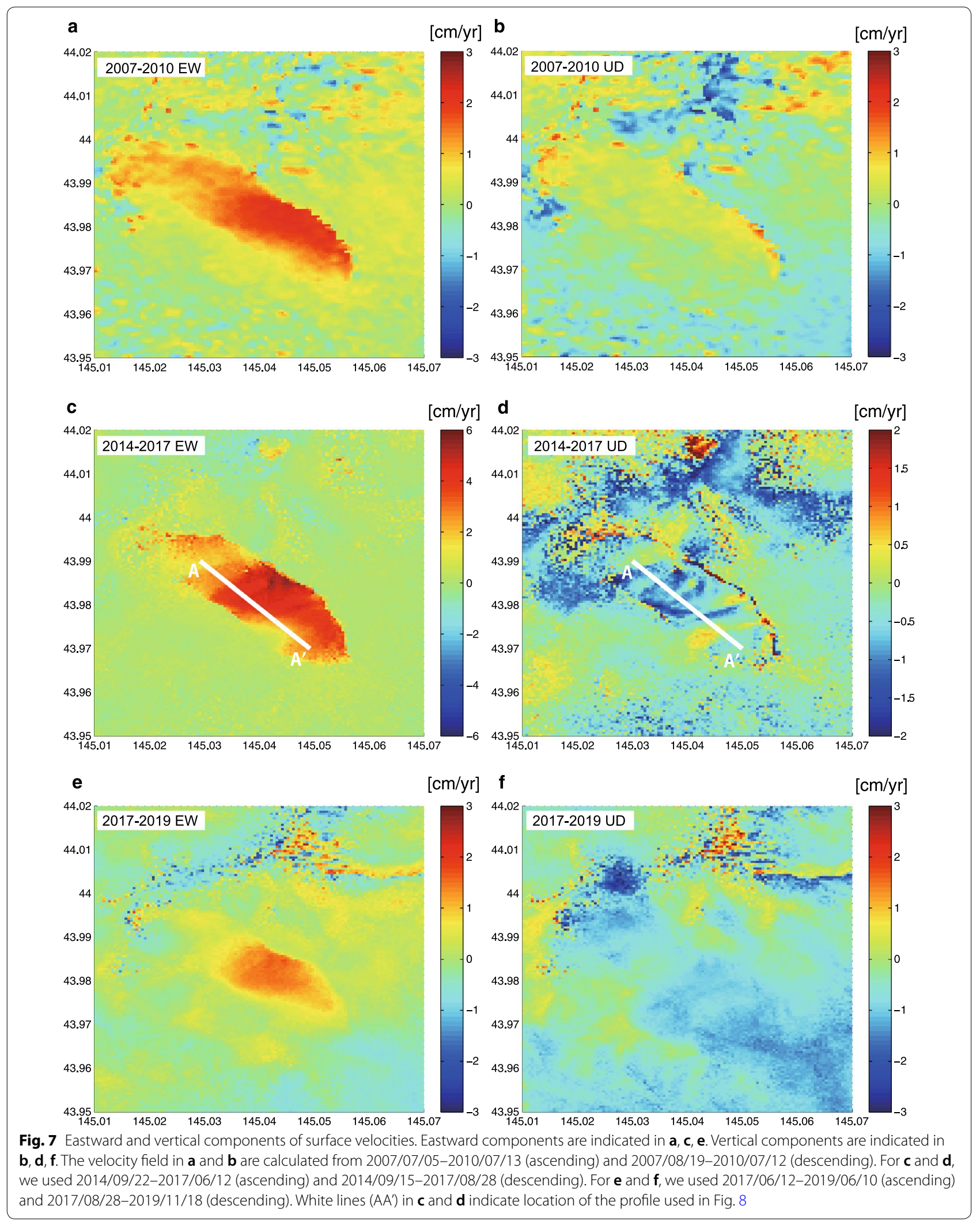






Fig. 8 One-dimensional profiles of surface velocities and surface gradient along A-A' in Fig. 7d. a Vertical component. b Eastward component. Blue lines indicate surface velocities. Green lines indicate surface gradient. Sign of the surface gradient is taken negative when the surface slope dips to the southeast (i.e., point A')

$$
\Delta u=\frac{B_{\perp} \Delta h}{R \sin \theta},
$$

where $B_{\perp}, R$, and $\theta$ denote the perpendicular baseline, distance between the satellite and the ground, and look angle, respectively (Hanssen, 2001). This equation states that the effect of DEHM error is proportional to the baseline length. In Fig. 7b, we cannot find clear periodic uplift unlike Fig. $7 d$, while the baseline length of the former is much larger $(>1000 \mathrm{~m})$ than the latter (Table 1). Therefore, the periodic uplift pattern in Figs. $7 \mathrm{~d}$ and 8 a should not be caused by the DEHM error. We further verify this conclusion quantitatively. We set $B_{\perp}, R$, and $\theta$ as $134 \mathrm{~m}, 8.02 \times 10^{5} \mathrm{~m}$, and 35.4 degrees, respectively, considering the interferogram 2014/09/15-2017/08/28, which is used for calculation of the uplift rate in Fig. $7 \mathrm{~d}$. Assuming that the periodic uplift rate in Figs. $7 d$ and 8 a were caused by the height error of the DEHM, we projected amplitude of the spatial change in the uplift rate $(0.5-1.5 \mathrm{~cm} / \mathrm{yr}$ as indicated in Fig. 8a) to the LOS direction, and multiplied temporal baseline of the interferogram, by which we obtain $\Delta u$ as $1.2-3.6 \mathrm{~cm}$. Then, following Eq. (1), we can estimate $\Delta h$ as $41.6-124.8 \mathrm{~m}$, which is far larger than the DEHM error officially announced by GSI $(5 \mathrm{~m})$. Thus, the periodic uplift rate in Figs. $7 \mathrm{~d}$ and $8 \mathrm{a}$ is not an artifact due to the DEHM error. To confirm advantages of the DEHM, we made a map of height difference between the DEHM and SRTM (Fig. 12). Here, we removed the geoid height of $30 \mathrm{~m}$ around the Shiretoko Peninsular (Kodama et al. 2014) from the DEHM. Figure 12 shows small height difference in the landslide area, where surface slope is gentle. The height difference is large in the area of steep surface slope especially around the main scarp. Figure 12b shows the height difference along the section line in Figs. $7 \mathrm{~d}$ and $12 \mathrm{a}$, which indicates periodic undulation with amplitude mostly ranging $2-15 \mathrm{~m}$, which is much smaller than $\Delta h$ that we estimated above. In conclusion, the spatial resolution of SRTM and the DEHM provided by GSI is 90 and $10 \mathrm{~m}$, respectively, and the latter is advantageous for removing topographic fringes associated with the small-scale surface topographies in the study area.

Next, we further discuss on the source of errors included in the interferograms that we processed. As we mentioned before, we have removed (1) long wave-length phase trend assuming a quadratic function in space, and (2) height-dependent phase assuming a linear function of altitude as well as linear phase trend in space. In spite of these efforts, we still find phase changes that seem not related to the landslide movements especially near the main ridge running along the highest part of Shiretoko Peninsular (Fig. 2). In Fig. 9f, for example, we find negative LOS displacements at the uppermost part of the landslide and to the northeast of the landslide (around $44.02 \mathrm{~N}, 145.05 \mathrm{E}$ ). Such noise is remarkable only at high altitude area $(>1000 \mathrm{~m})$, which does not strongly affect the LOS change detected in the middle to downstream area with relatively low elevation (Figs. 2 and 8). In this study, we did not apply advanced time-series analyses (e.g., Feretti et al. 2001; Berardino et al. 2002) so that the expected temporal change in the LOS would not be smoothed out. It turns out to be preferable, however, to 

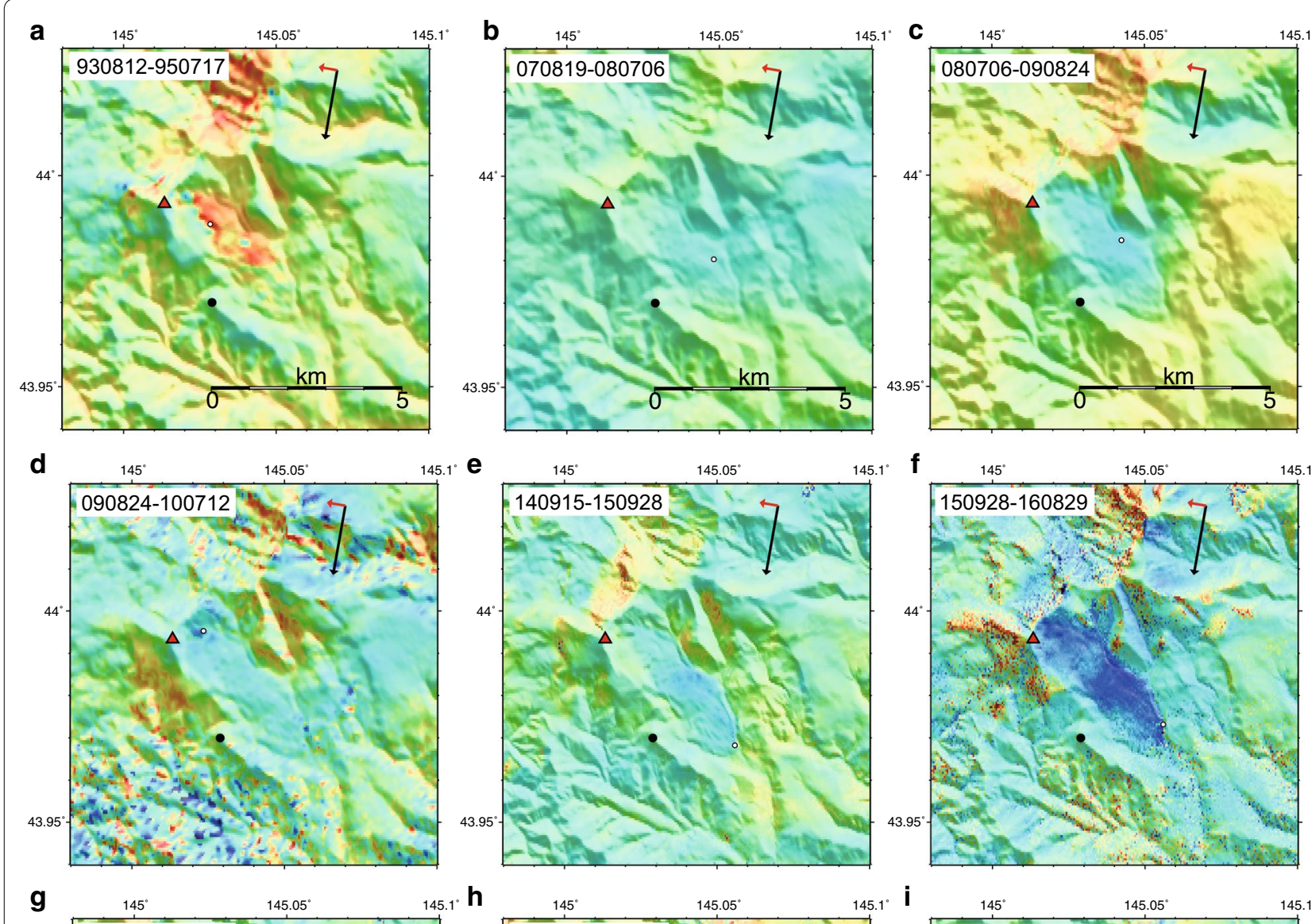

it. i
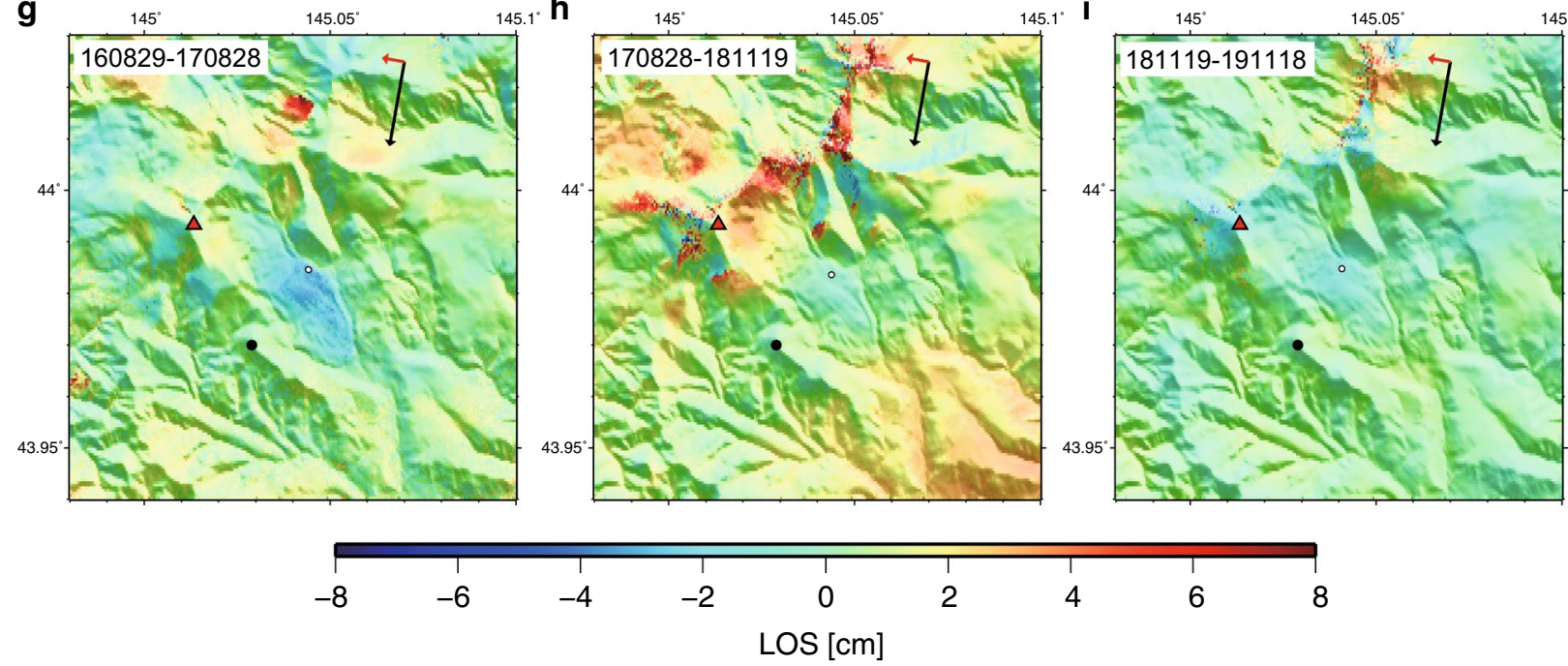

Fig. 9 Descending interferograms of short ( 1 year) temporal baseline. All the interferograms have been unwrapped. Top left figure is only one JERS-1 interferogram which exceptionally spans about 2 years. Black dot indicates the reference point. White dot indicates the fastest moving point within the landslide area. The orbit and LOS directions are indicated by black and red arrows, respectively. Red triangle indicates the summit of Mt. Onnebetsu-dake 

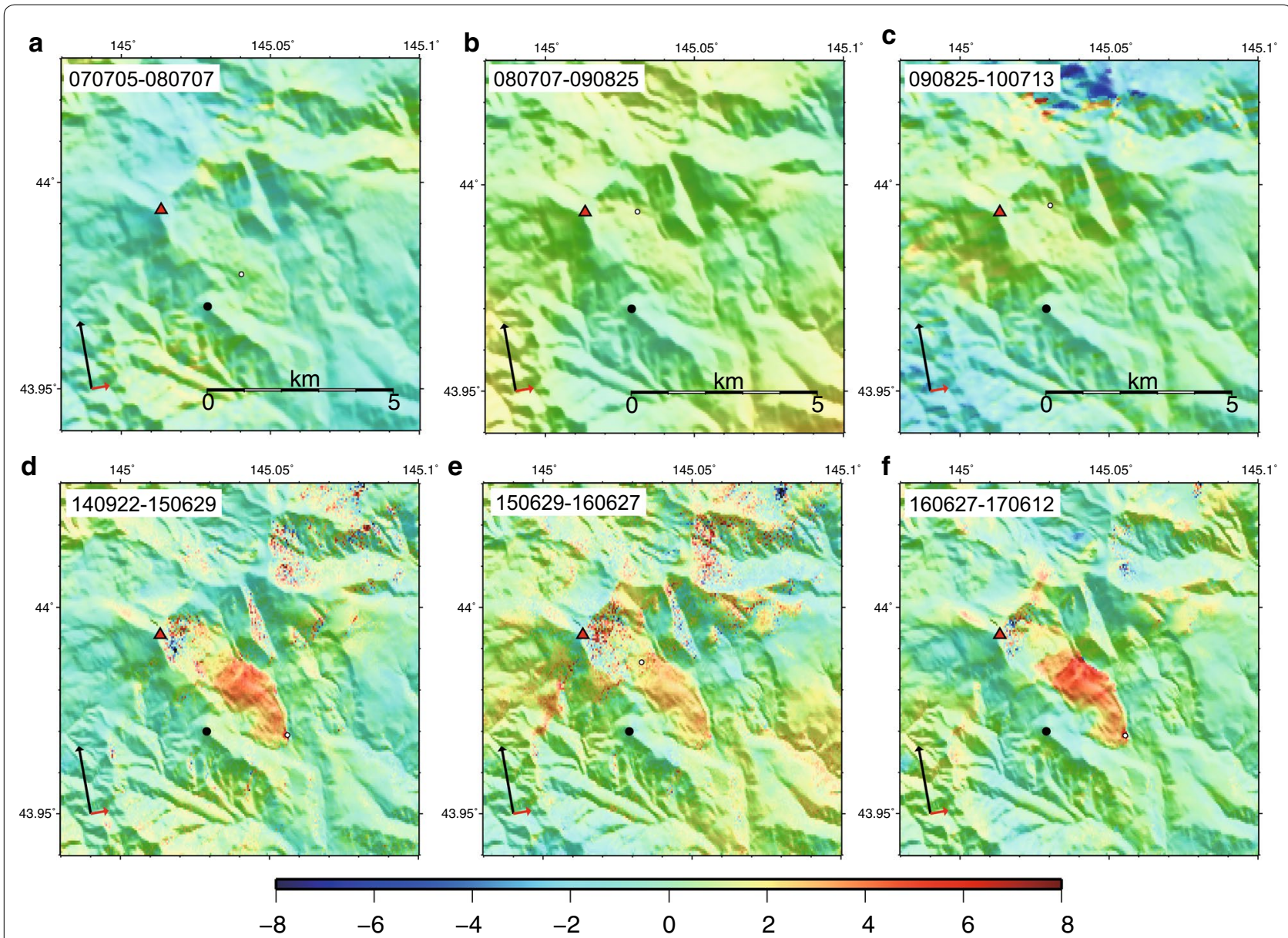

$-8$

$-4$

$-2$

0

2

4

$6 \quad 8$

LOS $[\mathrm{cm}]$

Fig. 10 Ascending interferograms with short ( 1 year) temporal baseline. All the interferograms have been unwrapped. Black dot indicates the reference point. White dot indicates the fastest moving point within the landslide area. The orbit and LOS directions are indicated by black and red arrows, respectively. Red triangle indicates the summit of Mt. Onnebetsu-dake

use such time-series analysis as Hu et al. (2019) to achieve higher precision over entire image with estimation of DEM error and phase delay caused by tropospheric disturbances, which is worth trying in the future.

Finally, we examine the effects of precipitation on landslide activities. Figure 13a indicates monthly precipitation at Utoro (Fig. 1), the nearest meteorological station $\sim 9 \mathrm{~km} \mathrm{NNW}$ of the Mt. Onnebestu-dake, from January 1993 to December 2019 (data provided by Japan Meteorological Agency). The data sampling interval is 1 month, and the gauge measures the precipitation as snow and rainwater combined. We also plotted the cumulative precipitation which is reset to zero every October 1 (Fig. 13b). An abnormally large amount of rainfall $(\sim 800 \mathrm{~mm}$ per month) was recorded during August 2016, which is caused by three typhoons passing by the Shiretoko Peninsula (e.g., Kitano et al. 2017) (Additional file 1. Fig. S1). The interferograms over August 2016 display fast movements of the entire landslide region (Figs. 9f and 10f). Such heavy rainfalls 


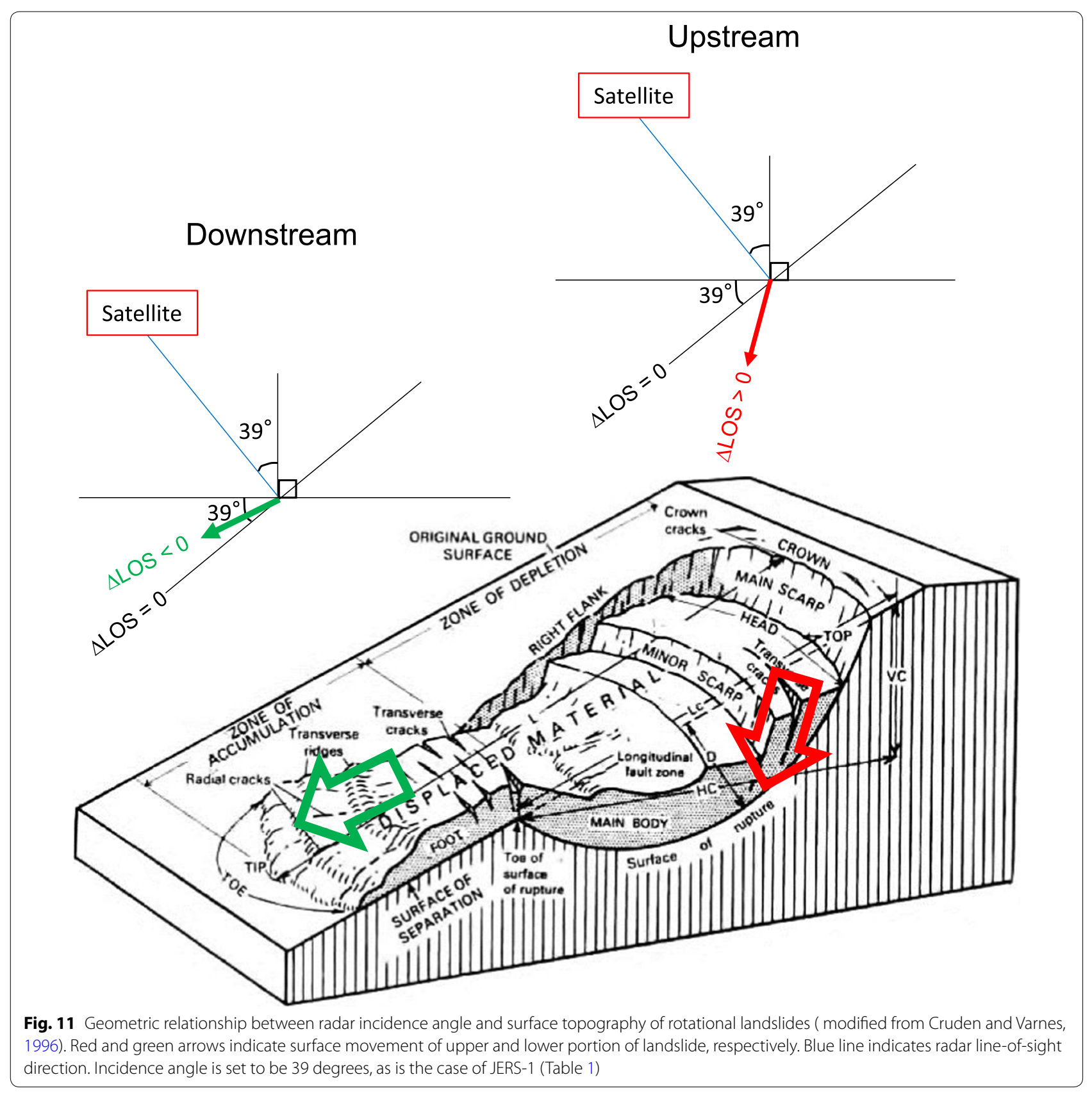



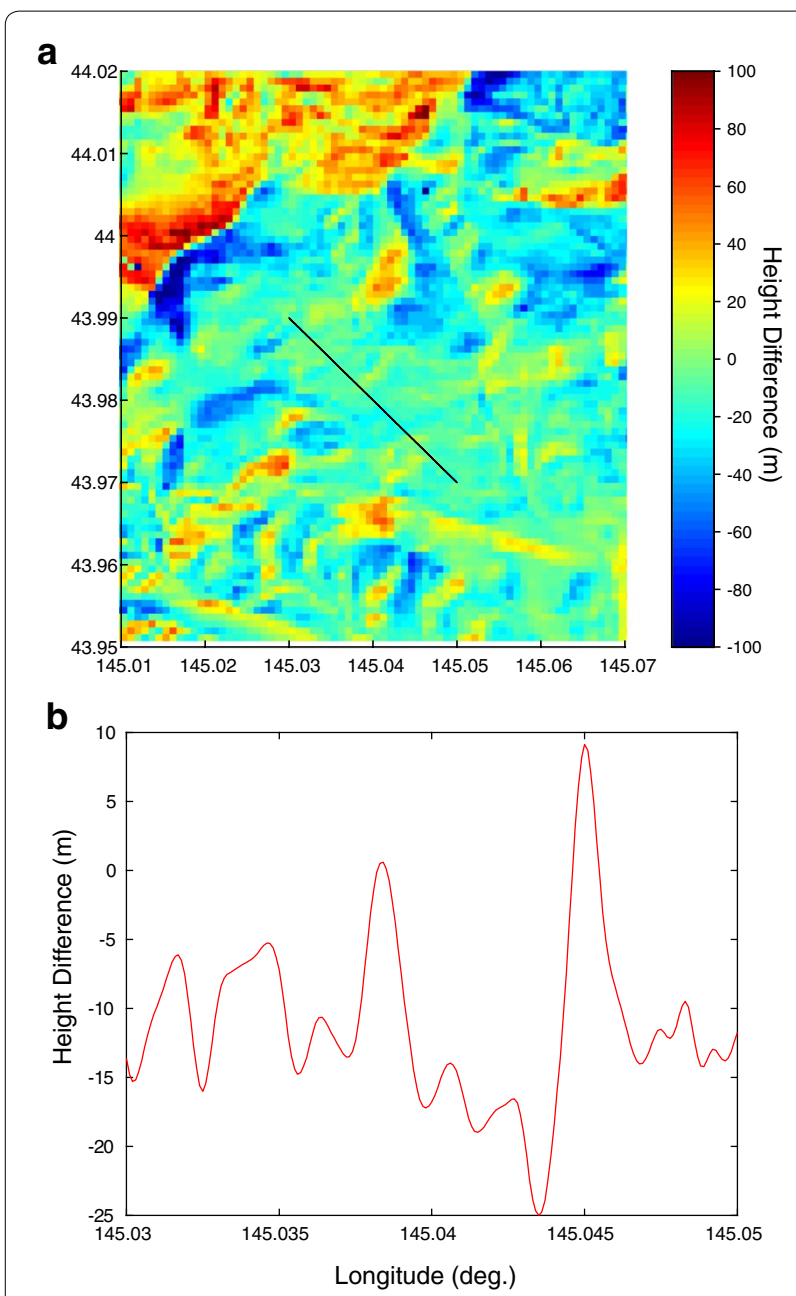

Fig. 12 Height difference between SRTM and DEHM provided by GSI. Geoid height was subtracted from the DEHM beforehand. a Map view of the height difference. Positive value indicates that the elevation of the DEHM is larger than that of SRTM. Black line indicates the section line A-A' in Fig. 7d. $\mathbf{b}$ Height difference along the profile A-A' in Fig. 7d

would increase pore-fluid pressure of the landslide material and reduce the frictional strength, which may increase the surface velocity of the landslide at the southeast flank of Mt. Onnebetsu-dake, as reported by previous studies (e.g., Iverson and Major, 1987; Handwerger et al. 2013; Hu et al. 2019). Unfortunately, the ALOS-2 data acquisition is not frequent enough to resolve the effect of typhoon passages in a few days (Additional file 1. Fig. S1). This problem should be investigated with the aid of more frequent Sentinel-1 data acquisition in the future. Next, we compare annual precipitation and surface velocity detected by long temporal baseline interferograms (Figs. 3 and 4). As indicated in Figs. 13b and 14, the annual precipitation at Utoro station seems slightly increasing with time. Total rainfall during 1995-1998, 2007-2010, and 2014-2017 are 4293, 4691, and $5530.5 \mathrm{~mm}$, respectively, which would account for faster landslide velocity during 2014-2017 (Figs. 3f and 4d) relative to that during 2007-2010 (Figs. 3d and 4b). But the difference in the deformation pattern between 1995-1998 and 2007-2010 (Fig. 3b and d) cannot be explained from the total amount of precipitation.

\section{Conclusion}

We investigated the spatiotemporal behavior of a large-scale landslide at the southeastern flank of Mt. Onnebestu-dake, in the Shiretoko Peninsula, from 1993 to the present using L-band SAR images acquired by three satellites. Many coherent interferograms over densely vegetated areas commonly indicate persistent movement of the landslide during this period, although SAR data have not been acquired during 1999-2005 and 2012-2013. We found pronounced temporal changes in the landslide velocity. In concrete, the positive LOS displacement is dominant in the upslope section during 1993-1998, and the negative LOS displacement is dominant in the middle and downslope section from 2007 to 2019 . The landslide velocity culminates during 2014-2017 where the eastward component reaches $6 \mathrm{~cm} / \mathrm{yr}$ while the vertical subsidence rate is $2 \mathrm{~cm} / \mathrm{yr}$ at most. The internal deformation pattern exhibits periodic uplift and/or subsidence consistent with topographic gradient, which can be observed only during 2014-2017. Heavy rainfall caused by three typhoons in August 2016 might have brought about an increase in the landslide velocity. Also, the annual amount of precipitation would be an important factor that prescribes the landslide velocity averaged over 3 years. To understand the physical mechanisms driving such remarkable spatiotemporal variations, further acquisition of L-band SAR images with shorter time intervals and ground-based field surveys with the aid of the information reported in this paper would be necessary. 

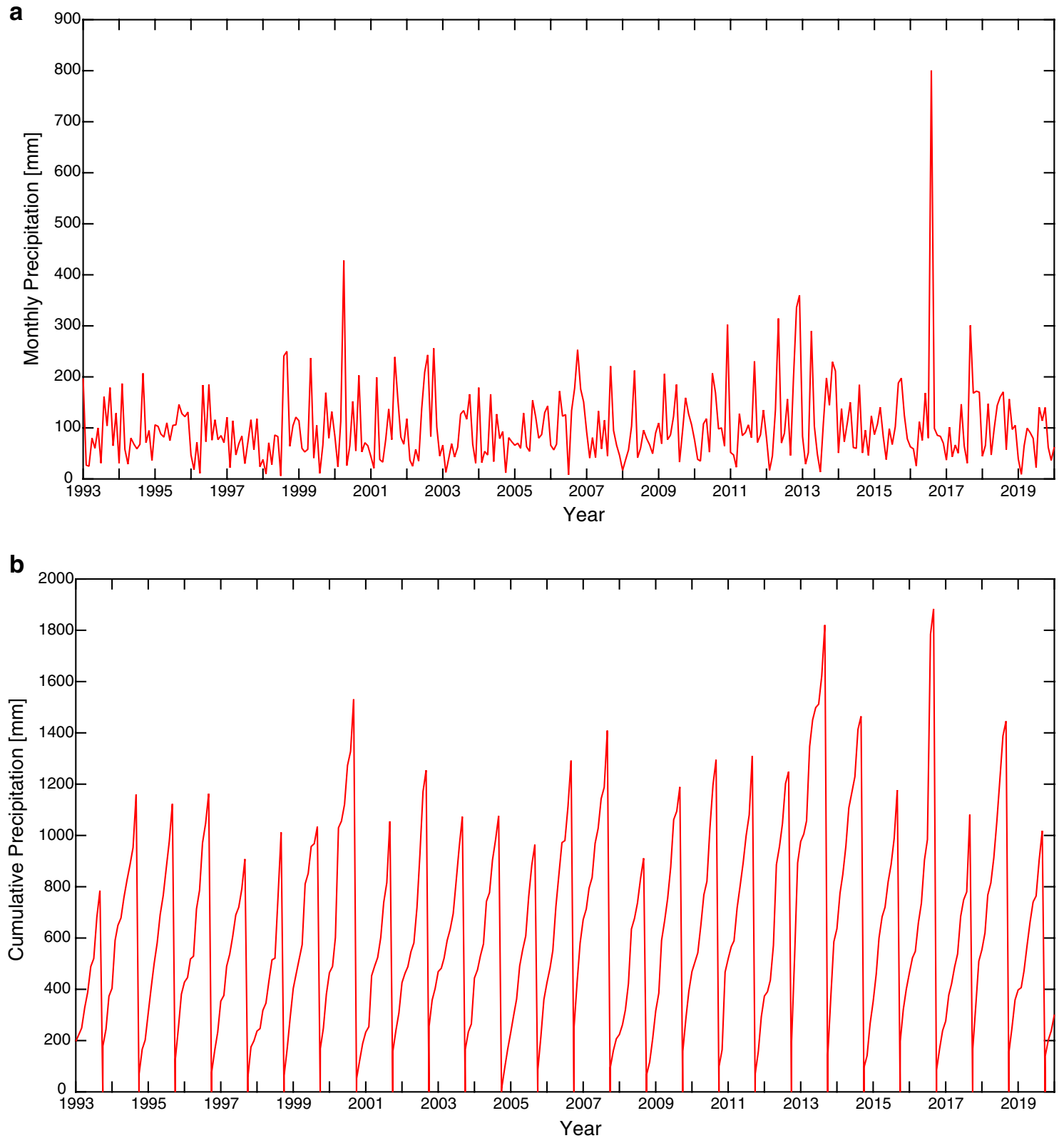

Fig. 13 Precipitation records at Utoro from January 1993 to December 2019. a Monthly precipitation. b Annual cumulative precipitation (reset to 0 on October 1st, every year). Data are provided from Japan Meteorological Agency (JMA). The location of Utoro is indicated in Fig. 1 


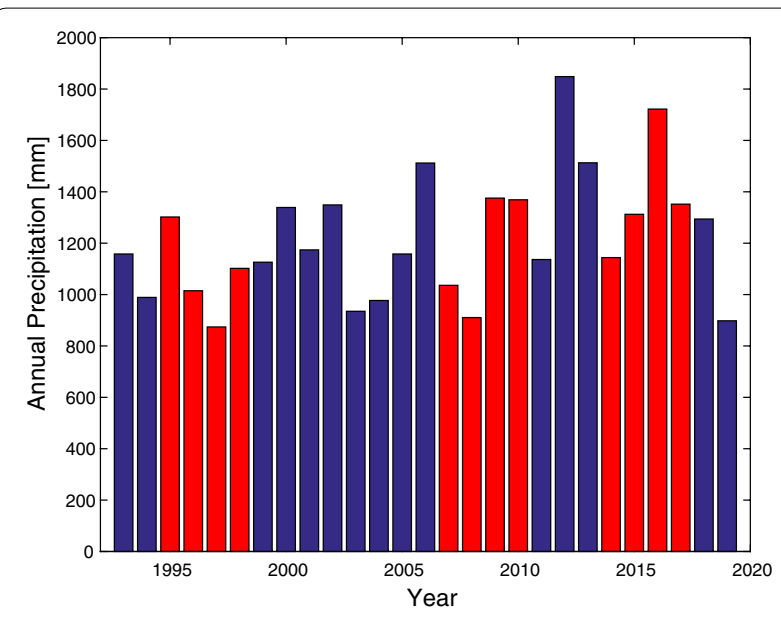

Fig. 14 Annual precipitation at Utoro from 1993 to 2019. Data are provided from JMA. The location of Utoro is indicated in Fig. 1. Data during 1995-1998, 2007-2010, and 2014-2017 are filled with red

\section{Supplementary information}

Supplementary information accompanies this paper at https://doi. org/10.1186/s40623-020-01265-4.

Additional file 1: Figure S1. Trajectories of three typhoons passing through Hokkaido in August 2016. Data are provided from JMA. Red line: Typhoon Chanthu. Gree line: Typhoon Mindulle. Blue line: Typhoon Kompasu. Circles with numbers indicate daily locations of the typhoon center at 9 AM (JST) and the date in August.

\section{Abbreviations}

DEHM: Digital Elevation Height Model; FBD: Fine beam dual polarization; FBS: Fine beam single polarization; InSAR: Interferometric SAR; JMA: Japan Meteorological Agency; J-SHIS: Japan Seismic Hazard Information Station; LOS: Line-of-sight; NIED: National Research Institute for Earthquake Science and Disaster Resilience; SAR: Synthetic Aperture Radar; SRTM: Shuttle Radar Topography Mission.

\section{Acknowledgements}

PALSAR and PALSAR2 data were provided from PIXEL (PALSAR Interferometry Consortium to Study our Evolving Land surface) under cooperative research contract between JAXA and ERI, University of Tokyo. PALSAR data were also provided from JAXA under ALOS-2 PI project. JERS-1 SAR data were provided from JAXA/METI through G-Portal. Part of the figures were created by Generic Mapping Tools (Wessel and Smith, 1998). We thank Masato Ohki and two anonymous reviewers for constructive comments, which greatly improved the quality of this paper.

\section{Authors' contributions}

YT managed this study and drafted the manuscript. GM prepared interferograms and related figures. Both authors read and approved the final manuscript.

\section{Funding}

Part of this study was supported by the Japan Society for Promotion of Science KAKENHI Grant Number 17 K05622.

\section{Availability of data and materials}

The datasets used and/or analyzed in this study are available from the authors upon request.
Ethics approval and consent to participate

Not applicable.

\section{Consent for publication}

Not applicable.

\section{Competing interests}

The authors declare that they have no competing interests.

\section{Author details}

${ }^{1}$ Department of Earth and Planetary Sciences, Hokkaido University, N10W8, Kita-ku, Sapporo 060-0810, Japan. ${ }^{2}$ Department of Natural History Sciences, Hokkaido University, N10W8, Kita-ku, Sapporo 060-0810, Japan.

Received: 8 April 2020 Accepted: 2 September 2020

Published online: 11 September 2020

\section{References}

Berardino P, Fornaro G, Lanari R, Sansosti E (2002) A new algorithm for surface deformation monitoring based on small baseline differential SAR interferograms. IEEE Trans Geosci Remote Sensing 40(11):2375-2383

Colesanti C, Wasowski J (2006) Investigating landslides with space-borne Synthetic Aperture Radar (SAR) interferometry. Eng Geol 88:173-199

Costantini M (1998) A novel phase unwrapping method based on network programming. IEEE Trans Geosci Remote Sens 36(3):813-821

Cruden DM, Varnes DJ (1996) Landslide types and processes. In: Turner KA, Schuster RL (eds) Landslides: investigation and mitigation. Transport Research Board Special Report, vol 247, pp 36-75. http://onlinepubs.trb. org/Onlinepubs/sr/sr247/sr247-003.pdf

Davis D, Suppe J, Dahlen FA (1983) Mechanics of fold-and-thrust belts and accretionary wedges. J Geophys Res 88(B2):1153-1172

Ferretti A, Prati C, Rocca F (2001) Permanent scatterers in SAR interferometry. IEEE Trans Geosci Remote Sensing 39(1):8-20

Fujiwara S, Nishimura T, Murakami M, Nakagawa H, Tobita M (2000) 2.5-D surface deformation of M6.1 earthquake near Mt Iwate detected by SAR interferometry. Geophys Res Lett 27:2049-2052

Fujiwara S, Morishita Y, Nakano T, Kobayashi T, Yarai H (2017) Non-tectonic liquefaction-induced large surface displacements in the Aso Valley, Japan, caused by the 2016 Kumamoto earthquake, revealed by ALOS-2 SAR. Earth Planet Sci Lett 474:457-465

Handwerger AL, Roering JJ, Schmidt DA (2013) Controls on the seasonal deformation of slow-moving landslides. Earth Planet Sci Lett 377-378:239-247

Hanssen R (2001) Radar interferometry: data interpretation and error analysis. Kluwer Academic Publishers, Dordrecht

Hilley GE, Bürgmann R, Ferretti A, Novali F, Rocca F (2004) Dynamics of slow-moving landslides from permanent scatterer analysis. Science 304(5679):1952-1955

Hu X, Bürgmann R, Lu Z, Handwerger AL, Wang T, Miao R (2019) Mobility, thickness, and hydraulic diffusivity of the slow-moving Monroe Landslide in California revealed by L-band satellite radar interferometry. J Geophys Res 124:7504-7518

Hu X, Lu Z, Pierson TC, Kramer R, George DL (2018) Combining InSAR and GPS to determine transient movement and thickness of a seasonally active low-gradient translational landslide. Geophys Res Lett 45:1453-1462. https://doi.org/10.1002/2017GL076623

Ito Y (1994) Characteristics of large-scale landslides in the Shiretoko Peninsular, Eastern Hokkaido Japan. Mem Kitami Inst Technol 26(1):15-28 (in Japanese with English abstract)

Ito Y (1996) Characteristics of landslide configurations and recent slope disasters in the Shiretoko Peninsular, East Hokkaido Japan. Landslides 33(3):32-41 (in Japanese with English abstract)

Iverson RM, Major JJ (1987) Rainfall, groundwater flow, and seasonal movement at Minor Creek landslide, northwestern California: physical interpretation of empirical relations. Geol Soc Am Bull 99(4):579-594

Jarvis A, Reuter HI, Nelson A, Guevara E (2008) Hole-filled seamless SRTM data V4, International Centre for Tropical Agriculture (CIAT). https://srtm.csi. cgiar.org. Accessed 26 Mar 2020 
Kitano Y, Yamamoto T, Kobayashi A, Yamada TJ (2017) Statistical analysis of typhoon related events in Hokkaido and surroundings in the last 56 years including the 2016 heavy rainfall. J Jpn Soc Civil Eng 73(4):1231-1236 (in Japanese with English abstract)

Kodama T, Miyahara B, Kawawa H, Nemoto S, Kuroishi Y (2014) Establishment of New Geoid Model "GSIGEO2011 (Ver. 1)". Bull GSI 126:67-85 (in Japanese)

Massonnet D, Rossi M, Carmona C, Adragna F, Peltzer G, Feigl K, Rabaute T (1993) The displacement field of the Landers earthquake mapped by radar interferometry. Nature 364:138-142

National Research Institute for Earth Science and Disaster Prevention (2020). https://www.j-shis.bosai.go.jp/, Accessed 27 Mar 2020

Nishiguchi T, Tsuchiya S, Imaizumi F (2017) Detection and accuracy of landslide movement by InSAR analysis using PALSAR-2 data. Landslides $14: 1483-1490$

Sato HP, Une H (2016) Detection of the 2015 Gorkha earthquake-induced landslide surface deformation in Kathmandu using InSAR images from PALSAR-2 data. Earth Planets Space 68:47

Terzaghi K (1950) Mechanism of landslides. In: Paige S (ed) Engineering Geology (Berkeley) Volume. Geological Society of America, New York, pp $83-123$
Varnes DJ (1978) Slope movement types and processes. In: Schuster RL, Krizek RJ (eds) Landslide, analysis and control, special report, vol 176. Transportation research board, National Academy of Science, Washington, pp $11-33$

Wegmüller U, Werner C (1997) Gamma SAR processor and interferometry software. In: Proceedings of the 3rd ERS symposium, vol SP-414. ESA, Florence, pp 1686-1692

Wessel P, Smith WHF (1998) New, improved version of generic mapping tools released. EOS Trans Am Geophys Union 79:579. https://doi. org/10.1029/98EO00426

Zhao C, Lu Z, Zhang Q, de la Fuente J (2012) Large-area landslide detection and monitoring with ALOS/PALSAR imagery data over Northern California and Southern Oregon, USA. Remote Sens Environ 124:348-359

\section{Publisher's Note}

Springer Nature remains neutral with regard to jurisdictional claims in published maps and institutional affiliations.

\section{Submit your manuscript to a SpringerOpen ${ }^{\circ}$ journal and benefit from:}

- Convenient online submission

- Rigorous peer review

- Open access: articles freely available online

- High visibility within the field

- Retaining the copyright to your article

Submit your next manuscript at $\boldsymbol{\nabla}$ springeropen.com 